\title{
Novice drivers' performance after different alcohol dosages and placebo in the divided-attention steering simulator (DASS)
}

\author{
Joris C. Verster • Anne E. Wester • Maartje Goorden • \\ Jan-Peter van Wieringen $\cdot$ Berend Olivier • \\ Edmund R. Volkerts
}

Received: 28 October 2008 / Accepted: 10 December 2008 / Published online: 6 January 2009

(C) The Author(s) 2008. This article is published with open access at Springerlink.com

\begin{abstract}
Rationale The divided-attention steering simulator (DASS) is designed to measure lane-keeping (i.e., a tracking task using a steering wheel) while performing a secondary visual task (responding to digits that appear in the corners of the computer screen). Some studies have already used the DASS, but the magnitude of impairment is difficult to interpret because reference values are lacking.

Objective To examine the magnitude of impairment after administration of four different dosages of alcohol and placebo.

Materials and methods Thirty-two healthy young adults participated in this randomized, single-blind crossover trial. Subjects received alcohol to gain a blood alcohol concentration (BAC) of $0.02 \%, 0.05 \%, 0.08 \%$, and $0.10 \%$ or alcohol-placebo. Sixteen subjects performed a 30-min test in DASS (dual-task condition). Outcome measures were steering error, reaction time, and percentage of errors. Sixteen other subjects performed the test without performing the secondary peripheral task (single-task condition).

Results Twenty-eight subjects (novice drivers; drivers' license up to 5 years) were included in the analyses. Dose-dependent impairment was found in both the singletask condition $\left(F_{(4,11)}=10.86, p<0.001\right)$ and the dual-task
\end{abstract}

The study is registered at http://www.clinicaltrials.gov (identifier NCT00223587).

J. C. Verster $(\bowtie) \cdot$ A. E. Wester • M. Goorden •

J.-P. van Wieringen $\cdot$ B. Olivier • E. R. Volkerts

Section Psychopharmacology, Faculty of Science,

Utrecht Institute for Pharmaceutical Sciences, Utrecht University,

P.O. Box 80082, 3508 TB Utrecht, The Netherlands

e-mail: j.c.verster@uu.nl condition $\left(F_{(4,9)}=5.58, p<0.015\right)$. Performance at all BAC levels differed significantly $(p<0.05)$ from alcohol-placebo, except BAC $0.02 \%$. With increasing BAC levels, subjects made more errors and reacted slower on the peripheral visual search task, but these effects did not reach significance.

Conclusion With increasing BAC, dose-dependent impairment was found. The DASS seems to be a suitable dividedattention task that is useful in psychopharmacological research and training of novice drivers.

Keywords DASS · Novice drivers · Driving · Alcohol · Cognitive

\section{Introduction}

The divided-attention steering simulator (DASS) is a relatively new test that enables the examination of skills related to driving. The DASS is a relatively simple test; the equipment consists of a steering wheel and a computer screen on which two lines represent a road that curves toward a horizon (see Fig. 1). Subjects have to keep a drawn representation of the front of a car at the center of a weaving road by using a steering wheel. At the same time, they have to respond to peripheral visual stimuli.

The DASS has been used in several studies showing impairment in fatigued long-distance drivers (Philip et al. 2003) and sleep apnea patients (Juniper et al. 2000; Hack et al. 2000; Turkington et al. 2004). Interpretation of the magnitude and clinical relevance of these effects remains problematic, given that no comparative data is available to index the level of impairment. For many tests, reference values obtained with different blood alcohol concentrations 


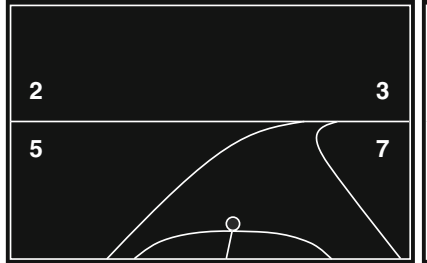

(A) Dual Task

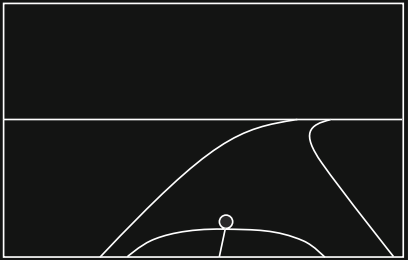

(B) Single Task
Fig. 1 Screen display of the DASS

(BACs) can be used as a historical control to illustrate and interpret research findings. Often, these BAC values correspond to the most common legal limits for driving a car, i.e., $0.02 \%, 0.05 \%, 0.08 \%$, and $0.10 \%$.

For example, results from the on-the-road driving test in real traffic (Verster et al. 2004, 2005) are interpreted by comparing the magnitude of weaving of the car (standard deviation of lateral position) with reference values obtained with different dosages of alcohol (Louwerens et al. 1987). The advantage of this approach is that the results of a study are immediately understandable for a broad readership that is not familiar with the testing methodology.

In this context, the present study examined the performance of novice drivers in the DASS under influence of four different dosages of alcohol $(0.02 \%, 0.05 \%, 0.08 \%$, and $0.10 \%$ ) and placebo.

\section{Materials and methods}

The study was a single-blind, randomized crossover trial comprising five test days separated by three to seven washout days. On each test day, subjects received placebo or one of four alcohol dosages $(0.02 \%, 0.05 \%, 0.08 \%$, or $0.1 \%$ ). Sixteen subjects performed the DASS without the secondary task, while the other 16 subjects performed the DASS as intended, i.e., including the secondary peripheral visual search task. The study was performed between March 2007 and February 2008. The study was approved by the university hospital medical ethics committee and performed according to the ICH guidelines for Good Clinical Practice and the Declaration of Helsinki and its latest amendments. All subjects gave their informed consent prior to their inclusion in the study.

\section{Subjects}

Thirty-two adult healthy volunteers (21-50 years old) with an equal representation of both genders (i.e., 16 men, 16 women) were recruited. Subjects had to be social drinkers (average of seven to 21 alcoholic drinks per week) and novice drivers (up to 5 years after obtaining drivers' license) to be included. Subjects were excluded in case of current drug use and pregnancy (a positive urine pregnancy screen), use of psychoactive medication, physical or mental illness, body mass index (BMI) $>30$, excessive alcohol use $(>21$ alcoholic drinks per week, excessive smoking $(>10$ cigarettes per day), or excessive caffeine use $(>5$ drinks per day).

\section{Procedure}

Each test day followed a standard program of activities (see Table 1). After arrival at the institute, urine was tested (InstantView) for the presence of amphetamines (including MDMA), barbiturates, cannabinoids, benzodiazepines, cocaine, and opiates, and a breath alcohol test was performed (Dräger Alcotest 7410 Breath Alcoholmeter). Nicotine intake was screened using a breath $\mathrm{CO}$ monitor (Smokelyzer). In women, a urine $\beta$-HCG pregnancy test was performed (InstantView). Thereafter, subjects were trained on the DASS and treatment was administered. As soon as the desired BAC was reached, the DASS test was performed.

The amount of alcohol needed to reach the desired BAC level was determined using the Widmarck formula, taking into account the gender and weight of the subject. Ethanol $(99 \%)$ was mixed with orange juice up to a volume of $250 \mathrm{~mL}$. The beverage was blinded by adding a taste marker (Menthae piperitae aetheroleum Ph.Eur.). Subjects consumed the beverage within 5 min while wearing a nose clip to further enhance treatment blinding. BAC measurements were made every $5 \mathrm{~min}$, both after treatment and placebo administration. The DASS test started as soon as the subject reached the desired peak BAC and alcohol levels started descending. BAC was also measured after performing the DASS test.

After a break, a second dose of alcohol was administered and the test day continued (results discussed elsewhere). $\mathrm{BAC}$ measurements continued throughout the day. At the

Table 1 Overview of a test day

\begin{tabular}{ll}
\hline Relative time & Activity \\
\hline 0 & Subject arrives at the institute \\
$0: 10$ & Urine drug screen (and pregnancy test in women) \\
$0: 15$ & Breath alcohol test and smoke test \\
$0: 30$ & DASS training session \\
$0: 45$ & Treatment administration \\
$1: 15^{\mathrm{a}}$ & DASS driving test \\
$1: 45$ & Subjective assessments \\
$1: 50$ & Breath alcohol test/break \\
\hline
\end{tabular}

${ }^{\text {a }}$ Starting time is variable depending on BAC. The test started as soon as the desired BAC was reached

${ }^{\mathrm{b}}$ After the break, a second dose of alcohol was administered and the test day continued (results discussed elsewhere) 
end of the test day, subjects could return home if the BAC reached zero or the subject and investigator agreed that the subject was able to safely leave the institute by public transportation.

Divided-attention steering simulator test

During screening, subjects were trained on the test to familiarize them with the test and achieve stable performance. Each test day, subjects were trained on the DASS (developed by Stowood Scientific Instruments, Oxford) in order to reduce learning effects (Juniper et al. 2000; Philip et al. 2003). After treatment administration, the actual test was performed in a sound-proof room. All tests comprised $30 \mathrm{~min}$.

The DASS is a combination of a tracking task and a peripheral visual search task, can be run on a standard PC, and has only one level of difficulty. A winding road is depicted as two drawn lines on the 19-in. computer screen and subjects are instructed to keep the front of the car within the road delineation (see Fig. 1). This can be achieved by using the steering wheel, which is fixed to the table in front of the computer screen. Subjects were seated approximately $50 \mathrm{~cm}$ in front of the 19-in. computer screen. Two parameters of steering error are measured: (1) the steering error relative to the center of the road $\left(\mathrm{SE}_{\mathrm{CENTER}}\right)$ and (2) the steering error from the ideal curve ( $\left.\mathrm{SE}_{\mathrm{CURVE}}\right)$. The steering error is measured in meters.

In addition to this steering task, the DASS also included a peripheral visual search task that has to be performed simultaneously. In this task, digits (0-9) are presented in the four corners of the screen. Every 8-10 s, the digits change randomly. Subjects were instructed to respond as quickly as possible by pushing one of the buttons left or right on the steering wheel when a number " 2 " appeared on the left or right side of the screen. The digit two appeared 39 times during the 30-min test. Reaction time and percentage of errors are parameters of the secondary peripheral visual search task.

In our study, half of the subjects performed only the steering component of the DASS (single-task condition), the other half performed the DASS including the peripheral visual search task (dual-task condition).
Subjective assessments

Visual analog scales of mental effort and subjective driving quality were completed after the test. Subjects also rated their drunkenness on a ten-point scale.

\section{Statistical analyses}

Statistical analyses were performed using SPSS. The data was tested for significance using repeated measures analysis of variance (two-tailed, $p \leq 0.05$ ). Within-subject factors were treatment (BAC $0 \%, 0.02 \%, 0.05 \%, 0.08 \%$, and $0.10 \%$ ) and treatment order. Results from the singletask and dual-task conditions were analyzed separately. Paired comparisons between different BAC levels and placebo were also conducted. Bonferroni's correction was applied to adjust for multiple comparisons. The dependent variables were steering error $\left(\mathrm{SE}_{\mathrm{CENTER}}\right.$ and $\mathrm{SE}_{\mathrm{CURVE}}$ ), reaction time, percentage of errors, and scores on the visual analog scales. In case the data did not meet the criteria of a normal distribution, nonparametric tests were applied. Sample size was estimated based upon results of previous studies using the DASS (Juniper et al. 2000; Turkington et al. 2004). Missing values were replaced by group averages for that particular BAC value.

\section{Results}

Subjects

A total of 28 subjects were included in the statistical analyses. Four subjects were excluded because they were not novice drivers (possession of a driver's license $>5$ years). Data from two test days was missing. One female had to vomit after BAC $0.05 \%$, another female after BAC $0.08 \%$. This missing data was replaced by the group average. The demographics are summarized in Table 2. The demographics of the subjects that performed the single task $(N=15)$ did not differ significantly from those who performed the dual task $(N=13)$.

Table 2 Demographics

\begin{tabular}{llll}
\hline & Dual-task group $(N=13)$ & Single-task group $(N=15)$ & Combined $(N=28)$ \\
\hline Number of subjects & 13 & 15 & 28 \\
Male/female ratio & $6 / 7$ & $6 / 9$ & $12 / 16$ \\
Age & $23.38(2.3)$ & $22.47(1.5)$ & $22.89(1.9)$ \\
BMI & $22.60(2.1)$ & $22.50(2.6)$ & $22.55(2.3)$ \\
Years driving & $2.71(1.6)$ & $3.48(1.3)$ & $3.12(1.4)$ \\
Kilometers per year & $4,191(4,224)$ & $4,219(7,998)$ & $4,206(6,638)$ \\
\hline
\end{tabular}

$B M I$ body mass index 
BAC levels and blinding

The actual BAC levels (mean $\pm \mathrm{SD}$ ) before testing matched the desired BAC for $0.02 \%(0.021 \pm 0.003 \%), 0.05 \%(0.05 \pm$ $0.005 \%), 0.08 \%(0.08 \pm 0.003 \%)$, and $0.10 \%(0.10 \pm 0.004 \%)$. Mean \pm SD BAC after the tests were $0.011 \pm 0.004 \%$ (BAC $0.02 \%$ ), 0.04 $\pm 0.009 \%$ (BAC $0.05 \%$ ), 0.06 $\pm 0.03 \%$ (BAC $0.08 \%$ ), and $0.08 \pm 0.01 \%$ (BAC $0.10 \%$ ). Blinding was successful: the group who performed the single-task DASS guessed their BAC levels correctly on $41.33 \%$ and $50.77 \%$ on single-task and dual-task test days, respectively.

\section{DASS performance}

Data was normally distributed and no effects of treatment order were found. The results are summarized in Table 3 and Fig. 2.

\section{Dual task performance}

For $\mathrm{SE}_{\mathrm{CENTER}}$, an overall effect of treatment was found $\left(F_{(4,9)}=5.58, p<0.015\right)$. Significant differences from placebo were found for BAC $0.05 \%\left(F_{(1,12)}=17.23, p<0.001\right)$, BAC $0.08 \%\left(F_{(1,12)}=19.99, p<0.001\right)$, and BAC $0.10 \%$ $\left(F_{(1,12)}=13.46, p<0.003\right)$. The difference between BAC $0.02 \%$ and placebo was not significant $\left(F_{(1,12)}=0.37, p<\right.$ 0.554). Although impairment is clearly dose-dependent, pairwise comparisons did not reveal significant differences between subsequent BAC levels (e.g., performance after BAC $0.05 \%$ did not differ significantly from performance after BAC 0.08\%).

For $\mathrm{SE}_{\mathrm{CURVE}}$, the overall treatment effect approached significance $\left(F_{(4,9)}=3.13, p<0.071\right)$. Significant differences from placebo were found for BAC $0.05 \%\left(F_{(1,12)}=7.91\right.$, $p<0.016)$, BAC $0.08 \%\left(F_{(1,12)}=10.67, p<0.007\right)$, and BAC $0.10 \% \quad\left(F_{(1,12)}=12.67, p<0.004\right)$. The difference between BAC $0.02 \%$ and placebo was not significant $\left(F_{(1,12)}=3.53, p<0.085\right)$.

Reaction time increased dose-dependently, but this effect did not reach significance $\left(F_{(4,9)}=3.06, p<0.075\right)$. A similar nonsignificant increment was observed for percentage of errors $\left(F_{(4,9)}=1.73, p<0.227\right)$.

\section{Single task performance}

An overall effect of treatment was found $\left(F_{(4,11)}=10.86\right.$, $p<0.001)$ for $\mathrm{SE}_{\mathrm{CENTER}}$. Significant differences from placebo were found for BAC $0.02 \%\left(F_{(1,14)}=6.55, p<\right.$ $0.023)$, BAC $0.05 \%\left(F_{(1,14)}=9.01, p<0.010\right)$, BAC $0.08 \%$ $\left(F_{(1,14)}=13.04, p<0.003\right)$, and BAC $0.10 \%\left(F_{(1,14)}=36.11\right.$, $p<0.0001)$. Pairwise comparisons did not reveal significant differences between subsequent BAC levels.

For $\mathrm{SE}_{\mathrm{CURVE}}$, the overall treatment effect was also significant $\left(F_{(1,14)}=13.51, p<0.0001\right)$. Significant differences from placebo were found for BAC $0.05 \%\left(F_{(1,14)}=\right.$ $7.60, p<0.015)$, BAC $0.08 \%\left(F_{(1,14)}=16.24, p<0.001\right)$, and BAC $0.10 \% \quad\left(F_{(1,14)}=39.83, p<0.0001\right)$. The difference between BAC $0.02 \%$ and placebo was not significant $\left(F_{(1,14)}=1.39, p<0.259\right)$.

\section{Single versus dual task comparison}

For both $\operatorname{SE}_{\text {CENTER }}\left(F_{(4,23)}=14.60, p<0.0001\right)$ and $\operatorname{SE}_{\text {CURVE }}\left(F_{(4,23)}=10.25, p<0.0001\right)$, the overall treatment effect differed significantly, indicating reduced performance in the dual-task condition $\left(F_{(1,14)}=13.51, p<0.0001\right)$. The difference between single and dual task was significant at each BAC level $(p<0.05)$.

Table 3 Results from the DASS and subjective assessments

\begin{tabular}{|c|c|c|c|c|c|c|}
\hline & PLAC & $0.02 \%$ & $0.05 \%$ & $0.08 \%$ & $0.10 \%$ & Overall effect \\
\hline \multicolumn{7}{|c|}{ Dual-task group $(N=13)$} \\
\hline $\mathrm{SE}_{\text {CENTER }}$ & $0.285(0.07)$ & $0.298(0.06)$ & $0.396(0.14)^{*}$ & $0.366(0.11)^{*}$ & $0.453(0.19)^{*}$ & $F_{(4,9)}=5.58, p<0.015$ \\
\hline $\mathrm{SE}_{\mathrm{CURVE}}$ & $0.238(0.04)$ & $0.266(0.05)$ & $0.297(0.09)^{*}$ & $0.314(0.10)^{*}$ & $0.399(0.17)^{*}$ & $F_{(4,9)}=3.13, p<0.071$ \\
\hline Reaction time (s) & $2.17(0.7)$ & $2.18(0.5)$ & $2.48(0.6)^{*}$ & $2.39(0.9)$ & $2.52(0.9)$ & $F_{(4,9)}=3.06, p<0.075$ \\
\hline Percentage of errors & $0.99(2.2)$ & $0.99(1.7)$ & $3.55(4.9)^{*}$ & $2.96(5.2)$ & $1.97(4.6)$ & $F_{(4,9)}=1.73, p<0.227$ \\
\hline Mental effort & $4.11(2.4)$ & $4.46(2.6)$ & $4.96(2.4)$ & $5.25(3.3)$ & $5.54(2.4)$ & $F_{(4,9)}=0.88, p<0.511$ \\
\hline Driving quality & $8.88(3.0)$ & $8.08(3.4)$ & $5.58(2.7)^{*}$ & $5.48(3.5)^{*}$ & $5.64(3.7)^{*}$ & $F_{(4,9)}=12.54, p<0.001$ \\
\hline \multicolumn{7}{|c|}{ Single-task group $(N=15)$} \\
\hline $\mathrm{SE}_{\text {CENTER }}$ & $0.175(0.05)$ & $0.222(0.09)^{*}$ & $0.241(0.11)^{*}$ & $0.279(0.14)^{*}$ & $0.299(0.11)^{*}$ & $F_{(4,11)}=10.86, p<0.001$ \\
\hline $\mathrm{SE}_{\mathrm{CURVE}}$ & $0.201(0.05)$ & $0.218(0.05)^{*}$ & $0.253(0.08)^{*}$ & $0.270(0.08)^{*}$ & $0.311(0.09)^{*}$ & $F_{(4,11)}=13.51, p<0.0001$ \\
\hline Mental effort & $3.99(1.9)$ & $5.51(2.7)$ & $5.77(2.5)$ & $5.63(2.8)$ & $6.03(1.9)$ & $F_{(4,11)}=1.27, p<0.340$ \\
\hline Driving quality & $10.89(4.1)$ & $8.40(4.2)$ & $8.07(4.3)^{*}$ & $7.02(3.8)^{*}$ & $5.91(3.7)^{*}$ & $F_{(4,11)}=3.30, p<0.052$ \\
\hline
\end{tabular}

$S E$ steering error

${ }^{*} p<0.05$, significant differences from placebo 
Fig. 2 Steering error (a $\mathrm{SE}_{\mathrm{CENTER}}$ and $\mathbf{b} \mathrm{SE}_{\mathrm{CURVE}}$ ) for the dual-task DASS after intake of alcohol. Best-fitting line and $95 \%$ confidence interval (dotted lines) are shown



(A) SE (CENTER)

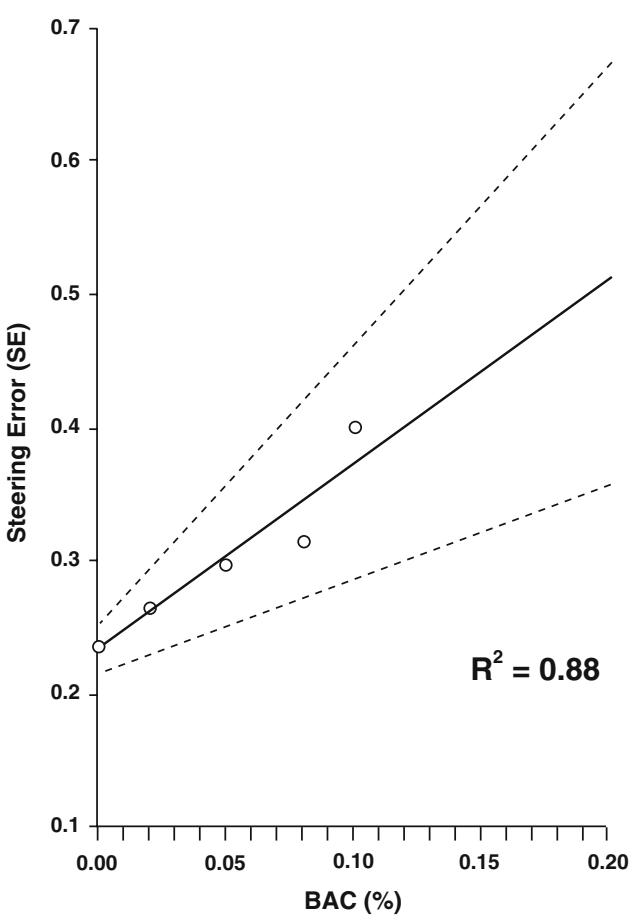

(B) SE (CURVE)

\section{Relationship between steering error and $B A C$}

As evident from Fig. 2, in the dual-task condition, a dosedependent increment in steering error was found. Best-fitting lines predicting steering error increment are of linear nature. The corresponding BAC levels can be computed as follows:

$$
\begin{array}{ccc}
\text { Dual task } & \triangle \mathrm{BAC}=\Delta \mathrm{SE}_{\mathrm{CENTER}} / 1.54 & \left(R^{2}=83 \%\right) \\
& \Delta \mathrm{BAC}=\Delta \mathrm{SE}_{\mathrm{CURV}} / 1.40 & \left(R^{2}=88 \%\right), \\
\text { Single task } & \triangle \mathrm{BAC}=\Delta \mathrm{SE}_{\mathrm{CENTER}} / 1.32 & \left(R^{2}=94 \%\right) \\
& \Delta \mathrm{BAC}=\Delta \mathrm{SE}_{\mathrm{CURVE}} / 1.03 & \left(R^{2}=97 \%\right) .
\end{array}
$$

Statistical analyses confirmed a highly significant linear dose-response relationship in the single-task condition for both $\operatorname{SE}_{\text {CENTER }}\left(F_{(1,14)}=32.8, p<0.0001\right)$ and $\mathrm{SE}_{\mathrm{CURVE}}$ $\left(F_{(1,14)}=55.3, p<0.0001\right)$. In the dual task, a similar linear dose-response relationship was found for $\mathrm{SE}_{\mathrm{CENTER}}$ $\left(F_{(1,12)}=14.7, p<0.002\right)$ and $\operatorname{SE}_{\mathrm{CURVE}}\left(F_{(1,12)}=12.2, p<\right.$ $0.004)$. Quadratic and higher-order relationships were not significant.

\section{Mental effort}

For both the single-task DASS $\left(F_{(4,11)}=1.27, p<0.275\right)$ and dual-task DASS $\left(F_{(4,9)}=0.88, p<0.511\right)$, mental effort to perform the test did not differ significantly for different BAC levels. Also, mental effort to perform the DASS did not differ between the single-task and dual-task groups $\left(F_{(1,26)}=0.74, p<0.397\right)$.
Subjective driving quality

After each test, subjective driving quality was rated. In the dual-task DASS, subjects rated their driving quality as worse with increasing BAC levels, a nearly significant effect $\left(F_{(4,11)}=3.30, p<0.052\right)$. Relative to placebo, performance was rated as significantly worse after BAC $0.05 \%$ $\left(F_{(1,14)}=4.62, p<0.049\right)$, BAC $0.08 \% \quad\left(F_{(1,14)}=9.55, p<\right.$ $0.008)$, and BAC $0.10 \%\left(F_{(1,14)}=11.11, p<0.005\right)$. Subjective driving quality for BAC $0.02 \%$ did not differ significantly from placebo $\left(F_{(1,14)}=2.66, p<0.125\right)$. In the single-task condition, a significant dose-dependent worsening of subjective driving quality was found $\left(F_{(4,9)}=\right.$ $12.54, p<0.001)$. In line with this, relative to placebo performance was rated as significantly worse after BAC $0.05 \%\left(F_{(1,12)}=11.95, p<0.005\right)$, BAC $0.08 \%\left(F_{(1,12)}=\right.$ $10.63, p<0.007)$, and $\mathrm{BAC} 0.10 \%\left(F_{(1,12)}=14.54, p<\right.$ $0.002)$. Subjective driving quality for BAC $0.02 \%$ did not differ significantly from placebo $\left(F_{(1,12)}=0.31, p<\right.$ $0.586)$. Subjective driving quality did not differ between the single-task and dual-task groups $\left(F_{(1,26)}=2.82\right.$, $p<0.105$ ).

\section{Reported drunkenness}

Subjects rated their drunkenness as significantly higher with increasing BAC levels $\left(F_{(4,24)}=61.55, p<0.0001\right)$. For all BAC levels, drunkenness was rated significantly higher when compared to placebo $(p<0.0001)$. 


\section{Gender effects}

Although the sample size does not allow comparisons between the performance of men and women for each BAC level, analyses indicate no significant gender effects for any of the objective and subjective variables.

\section{Discussion}

This study shows that the DASS is a sensitive test capable of measuring dose-dependent impairment after alcohol consumption. In fact, a linear relationship was found between BAC and the amount of steering error. Therefore, the DASS seems to be a suitable tool to test drug-induced impairment in psychopharmacological research.

By using BAC comparisons, it is easy to put the results obtained from previous studies using the DASS into perspective. For example, three studies have used the DASS to examine the performance of sleep apnea patients (Juniper et al. 2000; Hack et al. 2000; Turkington et al. 2004). Untreated patients with sleep apnea had a significant $\mathrm{SE}_{\text {CENTER }}$ increment of $0.12 \mathrm{~m}$ when compared to patients that were successfully treated with constant positive airway pressure. This increment in untreated apnea patients corresponds to a BAC level of $0.08 \%$, well above the legal limit for driving in most European counties. In longdistance drivers (average of $631 \mathrm{~km}$ before stopping), a significant steering error $\left(\mathrm{SE}_{\mathrm{CURVE}}\right)$ increment equaled $0.04 \mathrm{~m}$ relative to control subjects (Philip et al. 2003). Extrapolating our results, this increment in steering error corresponds to a BAC level of $0.03 \%$.

Peripheral scanning of the environment is essential during real driving and, therefore, including this secondary task in the DASS test is important. However, we did not observe significant dose-dependent increment in reaction time and percentage of errors in the secondary task. In line with previous research (Baulk et al. 2001), we found that performance of this secondary task does not interact with driving performance after different dosages of alcohol. Performing the secondary task does, however, seem to increase task load and reduce monotony, as evident from significantly increased steering error in the dual-task condition. Surprisingly, we observed significant performance differences between $\mathrm{BAC} 0.02 \%$ and placebo in the single-task condition, but not in the dual-task condition. We have no clear explanation for this unexpected finding. Given the theory of limited capacity, this finding was not expected. If attention has to be divided among two or more tasks, it is expected that performance on these tasks becomes worse than when one performs such tasks in isolation. Since the effect of BAC $0.02 \%$ on performance is relatively small, a bigger sample size would perhaps show significant results in the dual-task condition.

A limitation of our study is that we included only novice drivers. Future studies should test the effects of alcohol in more experienced drivers. Also, we tested relatively young healthy volunteers, while psychoactive medication is used often by adults and elderly. Given our sample size, we could not make reliable statistical comparisons between men and women. Gender differences should be addressed in future research as well. Data from actual highway driving shows that, after alcohol intake, women perform worse than men (Louwerens et al. 1987).

It remains to be determined if results obtained with the DASS can be translated to real driving. The most crucial concern in this context is the fact that the DASS lacks vital elements of real driving such as other traffic. However, the DASS may be useful for novice drivers to train lane-keeping and steering, i.e., basic skills at the operational level of driving. In conclusion, with increasing BAC, dose-dependent impairment was found. The DASS seems to be a suitable test that is useful in psychopharmacological research and training of novice drivers

Acknowledgment The authors have no conflicts of interest to disclose. The study was sponsored by internal university funding.

Open Access This article is distributed under the terms of the Creative Commons Attribution Noncommercial License which permits any noncommercial use, distribution, and reproduction in any medium, provided the original author(s) and source are credited.

\section{References}

Baulk SD, Reyner LA, Horne JA (2001) Driver sleepinessevaluation of reaction time measurement as a secondary task. Sleep 24:695-698

Hack M, Davies RJ, Mullins R, Choi SJ, Ramdassing-Dow S, Jenkinson C, Stradling JR (2000) Randomised prospective parallel trial of therapeutic versus subtherapeutic nasal continuous positive airway pressure on simulated steering performance in patients with obstructive sleep apnoea. Thorax 55(93):224-231

Juniper M, Hack MA, George CF, Davies RJ, Stradling JR (2000) Steering simulation performance in patients with obstructive sleep apnoea and matched control subjects. Eur Respir J 15(3): 590-595

Louwerens JW, Gloerich ABM, De Vries G, Brookhuis KA, O’Hanlon JF (1987) The relationship between drivers' blood alcohol concentration (BAC) and actual driving performance during high speed travel. In: Noordzij PC, Roszbach R (eds) Alcohol, drugs and traffic safety. Excerpta Medica, Amsterdam, pp 183-192

Philip P, Taillard J, Klein E, Sagaspe P, Charles A, Davies WL, Guilleminault C, Bioulac B (2003) Effect of fatigue on 
performance measured by a driving simulator in automobile drivers. J Psychosom Res 55(3):197-200

Turkington PM, Sircar M, Saralaya D, Elliott MW (2004) Time course of changes in driving simulator performance with and without treatment in patients with sleep apnoea hypopnoea syndrome. Thorax 59(1):56-59
Verster JC, Veldhuijzen DS, Volkerts ER (2004) Residual effects of sleep medication on driving ability. Sleep Med Rev 8:309-325

Verster JC, Veldhuijzen DS, Volkerts ER (2005) Is it safe to drive a car when treated with anxiolytics? Evidence from on-the-road driving studies during normal traffic. Curr Psychol Rev 1:215225 